\begin{tabular}{|c|c|}
\hline Citation & $\begin{array}{l}\text { Casaer MP, Wilmer A, (2014), } \\
\text { Role of disease and macronutrient dose in the randomized controlled } \\
\text { EPaNIC trial: a post hoc analysis. } \\
\text { Am J Respir Crit Care Med. } 2013 \text { Feb 1;187(3):247-55.Epub } 2012 \text { Nov } 29 .\end{array}$ \\
\hline Archived version & Final publisher's version / pdf \\
\hline Published version & http://dx.doi.org/10.1164/rccm.201206-09990C \\
\hline Journal homepage & http://www.ajrccm.org \\
\hline Author contact & $\begin{array}{l}\text { your email greet.vandenberghe@med.kuleuven.be } \\
\text { your phone number + } 32(0) 16344021\end{array}$ \\
\hline IR & https://lirias.kuleuven.be/handle/123456789/369734 \\
\hline
\end{tabular}

(article begins on next page) 


\title{
Role of Disease and Macronutrient Dose in the Randomized Controlled EPaNIC Trial
}

\section{A Post Hoc Analysis}

\author{
Michael P. Casaer ${ }^{1,2}$, Alexander Wilmer ${ }^{3}$, Greet Hermans ${ }^{2,3}$, Pieter J. Wouters ${ }^{1,2}$, Dieter Mesotten ${ }^{1,2}$, and \\ Greet Van den Berghe 1,2 \\ ${ }^{1}$ Laboratory and Department of Intensive Care Medicine and ${ }^{3}$ Medical Intensive Care Unit, University Hospitals Leuven, Leuven, Belgium; and \\ ${ }^{2}$ Department of Cellular and Molecular Medicine, KU Leuven, Leuven, Belgium
}

Rationale: Early parenteral nutrition to supplement insufficient enteral feeding during intensive care (early $\mathrm{PN}$ ) delays recovery as compared with withholding parenteral nutrition for 1 week (late PN). Objectives: To assess whether deleterious effects of early PN relate to severity of illness or to the dose or type of macronutrients.

Methods: Secondary analyses of a randomized controlled trial (EPaNIC; $n=4,640$ ) performed in seven intensive care units from three departments in two Belgian hospitals. In part 1, all patients were included to assess the effect of the randomized allocation to early $\mathrm{PN}$ or late $\mathrm{PN}$ in subgroups of patients with increasing-onadmission severity of illness. In part 2 , observationally, the association of the amount and type of macronutrients with recovery was documented in those patient cohorts still present in intensive care on Days 3, 5, 7, 10, and 14.

Measurements and Main Results: The primary end point was time to live discharge from the intensive care unit. For part 1, a secondary end point, acquisition of new infections, was also analyzed. All statistical analyses were performed by univariable and adjusted multivariable methods. In none of the subgroups defined by type or severity of illness was a beneficial effect of early PN observed. The lowest dose of macronutrients was associated with the fastest recovery and any higher dose, administered parenterally or enterally, was associated with progressively more delayed recovery. The amount of proteins/amino acids rather than of glucose appeared to explain delayed recovery with early feeding.

Conclusions: Early combined parenteral/enteral nutrition delayed recovery irrespective of severity of critical illness. No dose or type of macronutrient was found to be associated with improved outcome.

(Received in original form June 4, 2012; accepted in final form November 15, 2012) Supported by the Methusalem program of the Flemish Government (to G.V.d.B.). G.V.d.B. holds a European Research Council Advanced grant (AdvG-2012321670) from the Ideas Program of the European Union (FP7). Baxter Healthcare provided an unrestricted research grant that covered less than one-third of the costs of the study. The funders were not involved in the design of the study, the collection/analysis/interpretation of the data, or the preparation of this manuscript, or in the decision to submit this manuscript for publication. M.P.C. is a doctoral fellow and D.M. is a senior clinical investigator supported by the Research FundFlanders. G.H. is a postdoctoral fellow supported by the Leuven University Hospitals $\mathrm{KOF}$, clinical research grant.

Author Contributions: M.P.C., A.W., and G.V.d.B. contributed to the conception, design, analysis, and interpretation of the data; the drafting of the article; and final approval of the version to be published. G.H. and P.J.W. contributed to the analysis and interpretation of the data, the critical revision of the article for important critical content, and final approval of the version to be published. D.M. contributed to the analysis and interpretation of the data, the drafting of the article, and final approval of the version to be published.

Correspondence and requests for reprints should be addressed to Michael P. Casaer, M.D., Ph.D., Katholieke Universiteit Leuven, Department of Intensive Care Medicine, University Hospitals Leuven, Herestraat 49, B-3000 Leuven, Belgium. E-mail: michael.casaer@med.kuleuven.be

This article has an online supplement, which is available from this issue's table of contents at www.atsjournals.org

Am J Respir Crit Care Med Vol 187, Iss. 3, pp 247-255, Feb 1, 2013

Copyright $\odot 2013$ by the American Thoracic Society

Originally Published in Press as DOI: 10.1164/rccm.201206-0999OC on November 29, 2012 Internet address: www.atsjournals.org

\section{AT A GLANCE COMMENTARY}

Scientific Knowledge on the Subject

Recently, early parenteral nutrition to critically ill patients has been shown to prolong intensive care unit stay and provoke infections. It was not clear whether this effect could be attributed to less severely ill patients not benefiting from enhanced nutrition. Also, the role of nutrition dosing has been questioned.

What This Study Adds to the Field

This post hoc analysis shows no indication that more severely ill patients benefit from early parenteral nutrition. The untoward effect of early enhanced nutrition is not restricted to patients receiving the highest energy doses Also, a relatively high protein-to-glucose ratio is not associated with better outcome.

Clinical trial registered with www.clinicaltrials.gov (NCT 00512122).

Keywords: nutrition; critical illness; autophagy; sepsis; protein requirement

For decades, clinicians have attempted to improve outcome of critical illness by reducing the nutritional deficit, associated with morbidity $(1,2)$. The EPaNIC (Early Parenteral Nutrition to Supplement Insufficient Enteral Nutrition in Intensive Care) trial was methodologically designed and statistically powered to address this issue (3). In this randomized controlled trial, the strategy recommended by the European Guidelines (4) to initiate parenteral nutrition early, when enteral nutrition (EN) does not suffice to reach caloric targets in critically ill patients at risk of malnutrition (early $\mathrm{PN}$ ), was compared with the American/Canadian guidelines. The latter advise to tolerate hypocaloric enteral nutrition for 1 week in intensive care (late PN) (5). Tolerating hypocaloric feeding significantly increased the likelihood of earlier alive-discharge from the ICU and hospital, and reduced the rate of new infections and health care costs without compromising on mortality or functionality $(3,6)$.

The data generated by the EPaNIC trial raised three important new questions that were not fully addressed in the preplanned analyses $(3,7)$ : (1) First, it remained unclear whether the negative impact of early PN was consistent across the range of severity of illness. Indeed, more severely ill patients predictably develop a more pronounced caloric deficit. Hence these patients might benefit from early PN. In contrast, less severely ill patients might suffer more from the risks of such a preventive strategy (8-10). (2) As the EPaNIC results clearly support a strategy of lower calories early in ICU, a second question 
A Total Population

$(\mathrm{N}=4640)$

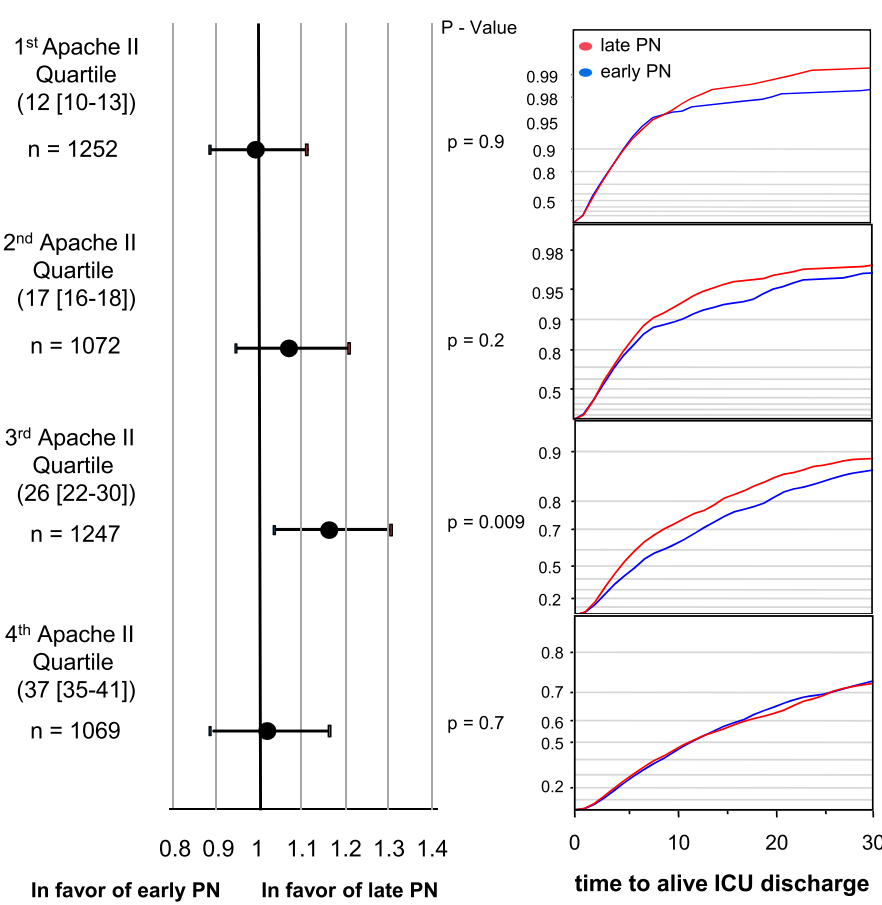

Likelihood of earlier alive ICU discharge (HR)

\section{Total Population $(\mathrm{N}=4640)$}

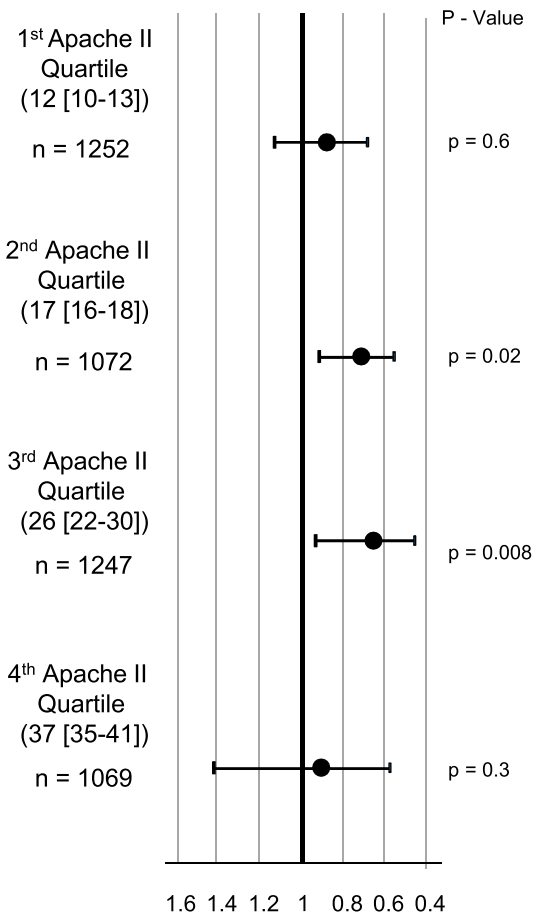

In favor of early PN In favor of late PN

OR for acquisition of a new infection
B

Other patients

$(\mathrm{N}=1822)$

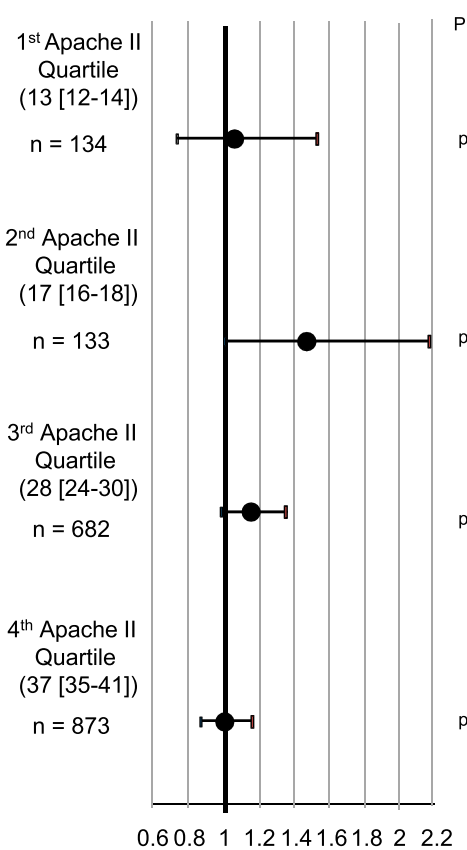

In favor of early PN In favor of late PN

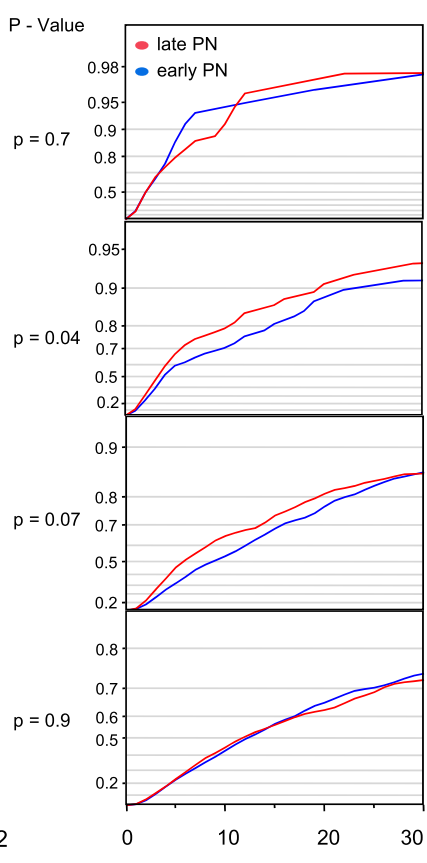

time to alive ICU discharge

Likelihood of earlier alive ICU discharge (HR)

D
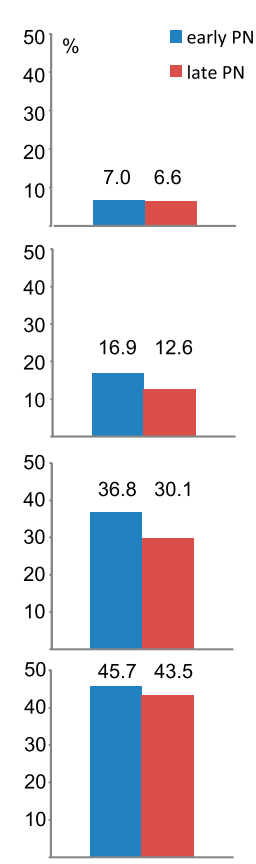

Patients acquiring a new infection during ICU stay
Other patients

( $N=1822)$

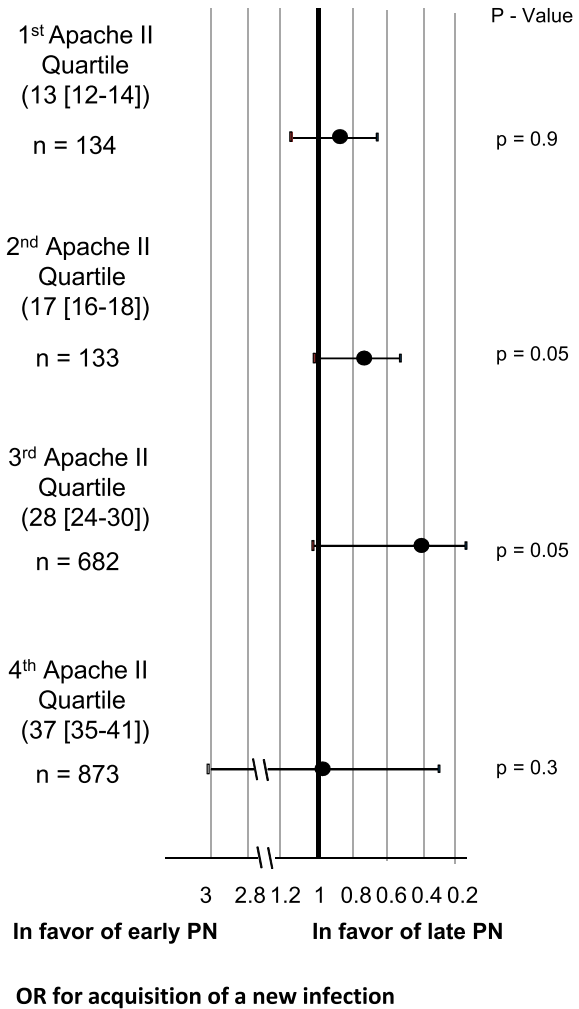

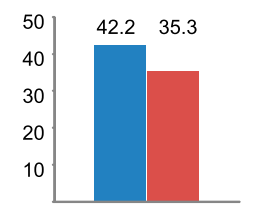

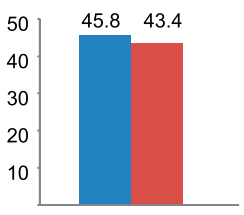

Patients acquiring a new infection during ICU stay 
Figure 1. Time to live discharge from the intensive care unit (ICU) and acquisition of a new infection with early parenteral (early PN) versus late PN (no PN during the first week in the ICU) in different-severity-of-illness subgroups. ( $A$ and $B$ ) Left: Hazard ratios (HRs) and confidence intervals (Cls) (plus $P$ value) for an earlier alive-ICU-discharge with early versus late PN in patient quartiles defined by APACHE II score. ( $A$ and $B$ ) Right: KaplanMeier curves depicting the proportion of patients discharged alive from the ICU on ICU Days 1-30. (C and D) Left: Odds ratios (ORs) and Cls for acquisition of a new infection in ICU with early versus late PN (plus $P$ value). ( $C$ and $D$ ) Right: Crude proportion of patients acquiring a new infection in the ICU. ( $A$ and $C$ ) Total study population. ( $B$ and $D$ ) Other patients; these are the patients admitted to the medical ICU, admitted for medical reasons after surgery, or admitted after complex surgery (including trauma and burns). Whereas Kaplan-Meier curves depict only the first 30 days in ICU, the hazard ratios, in contrast, are based on every patient's entire ICU stay. APACHE = Acute Physiology and Chronic Health Evaluation.

concerned whether there is a dose dependency between total macronutrient dose and outcome. Nonrandomized studies have suggested that a moderate dose of nutrition administered early would result in improved outcome as compared with full-dose artificial feeding (11-13). (3) The third item concerns the possible differential contribution of the type of macronutrients, more specifically glucose versus protein, to the observed adverse outcome with early PN. Indeed, it has been suggested that the amounts of glucose administered parenterally in the early-PN arm could exceed oxidation capacity (14). Moreover, the standard premixed PN formula in EPaNIC, although used in routine clinical practice, delivered less protein than recommended by nutrition guidelines $(4,5)$. The specific association between glucose versus protein/amino acid intake and clinical outcome was thus assessed.

In this secondary analysis of the EPaNIC trial, we first tested the hypothesis that the observed deleterious impact of early PN on recovery from critical illness was limited to the less severely ill patients in an analysis of the randomized intervention in post hoc subgroups defined by severity of disease. We then studied, observationally, the association of cumulative total energy, glucose, and protein doses with recovery.

\section{METHODS}

The study design, methodology, and population have been reported previously $(3,7)$. In brief, the EPaNIC trial was a randomized, controlled, investigator-initiated trial in seven ICUs from three departments in a university and a regional hospital in Belgium. After informed consent was obtained, 4,640 adult surgical and medical ICU patients were randomized on admission, to early PN and late PN. In the early-PN group, glucose- $20 \%$ was initiated on Day 1 and followed by PN (OliClinomel or Clinimix; Baxter, Brussels, Belgium) on Day 3, unless adequate enteral/ oral nutrition was predicted by the treating physician, $\mathrm{PN}$ was targeted to reach, cumulated with the EN given, the caloric target by the end of Day 4 . In the late-PN group, no PN was given until Day 8. Patients in both arms, unless they were ready for oral nutrition, received EN from Day 2 on, except when medically contraindicated. Parenteral micronutrients were administered identically in both groups.

Energy target calculations, including protein calories, were based on ideal body weight, age, and sex (3).

The protocol was approved by the institutional review boards and by the Belgian authorities. Outcome assessors were blinded $(3,7)$.

\section{Effect of Early PN versus Late PN in Subgroups of Patients with Increasing Severity of Illness}

This post hoc subgroup analysis included all 4,640 patients in the intention-to-treat population. The effect of the randomized intervention was assessed separately within four subgroups representing increasing severity of illness, defined by admission APACHE II (Acute Physiology and Chronic Health Evaluation II) score. This analysis was repeated after eliminating post-cardiac surgery patients, generally considered less sick, although less quantifiable by APACHE II $(10,15)$. This subgroup $(\mathrm{n}=1,822)$, further referred to as "other patients," thus comprised patients admitted to the medical ICU, patients admitted for medical complications after surgery, and patients admitted after complex noncardiac surgery. The effect on the primary end point, duration of intensive care dependency, was analyzed by "time-to-event analysis," censoring ICU nonsurvivors beyond the longest-staying ICU survivor $(3,7)$. As mortality and ICU stay were known for all patients, this was the only form of censoring (16). This "time-to-alive ICU discharge" analysis of the competing risks "ICU discharge" and "death in ICU" avoids informative censoring (16).

In addition, the impact of the randomized intervention on acquisition of a new infection in the ICU, assessed by blinded experts (3), was analyzed within these eight subgroups.

Analyses were performed both in a univariable and multivariable manner, adjusted for type and severity of illness, age, body mass index, and Nutritional Risk Screening score (17) on ICU admission. The "time-to-alive ICU discharge" was visualized by Kaplan-Meier plots and analyzed by adjusted proportional hazards analysis. Moreover, odds ratios (ORs) for being discharged alive from the ICU within 8 days were estimated by adjusted logistic regression analysis. The crude proportions of patients acquiring new infection were visualized by bar charts, with the odds ratios estimated by adjusted logistic regression analysis.

Interaction between APACHE II score quartiles and randomization, in the analyses of ICU dependency and of infections, was tested at a significance level of less than 0.1 . The proportional hazards assumption for early $\mathrm{PN}$ versus late $\mathrm{PN}$ was verified by analysis of log-minus-log plots. The $P$ value for significance in the analyses in four strata was set at 0.0125 .

\section{Association between Dose of Macronutrients and Recovery from Critical Illness}

This observational analysis studied the association between nutrition given up to a specific day and recovery thereafter, in patients still present in the ICU on Days 3, 5, 7, 10, and 14 after admission. All patients present in the ICU on these prespecified days were included when they achieved less than minimal caloric intake by mouth $(<30 \%$ of nutritional target). The association between total macronutrient intake, quantified by cumulative total energy intake-the amount of calories, encompassing carbohydrates, lipid, and protein received from ICU admission until the analysis day and expressed in percentages of calculated caloric target per day-and "time-to-alive ICU discharge" was assessed by adjusted proportional hazards analysis. The proportional hazards assumption for cumulative energy on Day 3 was verified by analysis of partial residuals over time. To provide information on the shape of the relationship between cumulative energy intake and timeto-alive ICU discharge, it was divided into intervals of percentage of target (20\% of target increments starting at $30 \%$ of target). Time-toalive ICU discharge functions for these intervals were visualized by Kaplan-Meier plots and effect size was estimated by adjusted Cox proportional hazards analyses. In addition, on Day 3, ORs for being discharged alive from the ICU within 8 days were determined. To exclude splitting related artifacts, these analyses were repeated using a second set of intervals with different boundaries ( $20 \%$ of target increments starting at $20 \%$ of target). These cumulative energy analyses were performed within the early-PN group alone, the late-PN group alone, and in the total population.

\section{Association between Glucose Dose versus Protein/Amino Acid Dose and Recovery from Critical Illness}

The protein/amino acid and lipid doses in the EPaNIC trial were closely linked because of the standard PN and EN solutions used. The timing of the conversion from exclusive glucose $5 \%$ or $20 \%$ infusions to $\mathrm{PN} \pm \mathrm{EN}$ and initial glucose over protein/amino acid ratios, however, were 
TABLE 1. DEMOGRAPHICS OF PATIENTS IN QUARTILES BASED ON ADMISSION APACHE II SCORE: TOTAL EPaNIC POPULATION

\begin{tabular}{|c|c|c|c|c|c|c|c|c|c|c|c|c|}
\hline & \multicolumn{3}{|c|}{ APACHE Quartile I: 12 (10-13) } & \multicolumn{3}{|c|}{ APACHE Quartile II: 17 (16-18) } & \multicolumn{3}{|c|}{ APACHE Quartile III: $26(22-30)$} & \multicolumn{3}{|c|}{ APACHE Quartile IV: 37 (35-41) } \\
\hline & Early PN & Late PN & $P$ Value & Early PN & Late PN & $P$ Value & Early PN & Late PN & $P$ Value & Early PN & Late PN & $P$ Value \\
\hline $\mathrm{n}$ & 626 & 626 & & 540 & 532 & & 608 & 639 & & 538 & 531 & \\
\hline Age, yr & $60.4( \pm 14.2)$ & $60.9( \pm 14.7)$ & 0.70 & $69.9( \pm 10.6)$ & $69.7( \pm 10.2)$ & 0.35 & $62.0( \pm 15.8)$ & $62.0( \pm 16.8)$ & 0.50 & $64.2( \pm 13.7)$ & $64.2( \pm 14.8)$ & 0.50 \\
\hline BMI, mean $( \pm S D)$ & $27.0( \pm 4.6)$ & $27.0( \pm 4.4)$ & 0.45 & $26.6( \pm 4.6)$ & $26.3( \pm 4.3)$ & 0.14 & $26.5( \pm 5.0)$ & $25.8( \pm 4.8)$ & 0.006 & $26.0( \pm 5.8)$ & $25.8( \pm 5.1)$ & 0.27 \\
\hline NRS, median (IQR) & $3(3-4)$ & $3(3-4)$ & 0.86 & $4(3-4)$ & $4(3-4)$ & 0.21 & $4(3-4)$ & $4(3-4)$ & 0.69 & $4(3-5)$ & $4(3-5)$ & 0.53 \\
\hline Cancer, n (\%) & $69(11.0 \%)$ & $73(11.7 \%)$ & 0.78 & $99(18.3 \%)$ & $102(19.2 \%)$ & 0.75 & $105(17.3 \%)$ & $139(21.8 \%)$ & 0.053 & $164(30.5 \%)$ & $143(26.9 \%)$ & 0.22 \\
\hline Diagnostic category on admission, $\mathrm{n}(\%)$ & & & 0.26 & & & 0.31 & & & 0.98 & & & 0.83 \\
\hline \multicolumn{13}{|l|}{ Surgical admissions } \\
\hline Cardiac surgery & $556(88.8 \%)$ & $562(89.8 \%)$ & & $477(88.3 \%)$ & $462(86.8 \%)$ & & $274(45.1 \%)$ & $291(45.5 \%)$ & & $103(19.1 \%)$ & $93(17.5 \%)$ & \\
\hline Complicated abdominal or pelvic surgery & $33(5.3 \%)$ & $20(3.2 \%)$ & & $18(3.3 \%)$ & $27(5.1 \%)$ & & $49(8.1 \%)$ & $59(9.2 \%)$ & & $70(13.0 \%)$ & $72(13.6 \%)$ & \\
\hline Transplantation & $1(0.1 \%)$ & $0(0.0 \%)$ & & $1(0.2 \%)$ & $0(0.0 \%)$ & & $45(7.4 \%)$ & $42(6.6 \%)$ & & $118(21.9 \%)$ & $121(22.8 \%)$ & \\
\hline Trauma: burns or reconstructive surgery & $2(0.3 \%)$ & $6(1.0 \%)$ & & $7(1.3 \%)$ & $6(1.1 \%)$ & & $66(10.9 \%)$ & $64(10.0 \%)$ & & $24(4.5 \%)$ & $31(5.8 \%)$ & \\
\hline Complicated thoracic surgery & $16(2.3 \%)$ & $17(2.7 \%)$ & & $14(2.6 \%)$ & $11(2.1 \%)$ & & $25(4.1 \%)$ & $25(3.9 \%)$ & & $31(5.8 \%)$ & $30(5.6 \%)$ & \\
\hline Complicated vascular surgery & $8(1.3 \%)$ & $13(2.1 \%)$ & & $15(2.8 \%)$ & $9(1.7 \%)$ & & $18(3.0 \%)$ & $15(2.4 \%)$ & & $24(4.5 \%)$ & $32(6.0 \%)$ & \\
\hline Complicated neurosurgery & $3(0.5 \%)$ & $0(0.0 \%)$ & & $1(0.2 \%)$ & $0(0.0 \%)$ & & $39(6.4 \%)$ & $40(6.3 \%)$ & & $18(3.4 \%)$ & $14(2.6 \%)$ & \\
\hline Neurological disease & $0(0.0 \%)$ & $0(0.0 \%)$ & & $0(0.0 \%)$ & $0(0.0 \%)$ & & $10(1.6 \%)$ & $14(2.2 \%)$ & & $4(0.7 \%)$ & $1(0.2 \%)$ & \\
\hline \multicolumn{13}{|l|}{ Medical admissions } \\
\hline Respiratory & $1(0.2 \%)$ & $2(0.3 \%)$ & & $1(0.2 \%)$ & $3(0.3 \%)$ & & $24(4.0 \%)$ & $24(3.8 \%)$ & & $46(8.6 \%)$ & $42(7.9 \%)$ & \\
\hline Gastroenterologic or hepatic & $2(0.3 \%)$ & $1(0.2 \%)$ & & $1(0.2 \%)$ & $4(0.8 \%)$ & & $20(3.3 \%)$ & $21(3.3 \%)$ & & $32(6.0 \%)$ & $35(6.6 \%)$ & \\
\hline Hematological or oncological & $0(0.0 \%)$ & $0(0.0 \%)$ & & $0(0.0 \%)$ & $1(0.2 \%)$ & & $5(0.8 \%)$ & $4(0.6 \%)$ & & $13(2.4 \%)$ & $11(2.1 \%)$ & \\
\hline Cardiovascular & $0(0.0 \%)$ & $0(0.0 \%)$ & & $0(0.0 \%)$ & $0(0.0 \%)$ & & $3(0.5 \%)$ & $2(0.3 \%)$ & & $5(0.9 \%)$ & $8(1.5 \%)$ & \\
\hline Renal & $0(0.0 \%)$ & $0(0.0 \%)$ & & $0(0.0 \%)$ & $0(0.0 \%)$ & & $0(0.0 \%)$ & $3(0.5 \%)$ & & $8(1.5 \%)$ & $7(1.3 \%)$ & \\
\hline Neurological & $0(0.0 \%)$ & $0(0.0 \%)$ & & $1(0.2 \%)$ & $0(0.0 \%)$ & & $3(0.5 \%)$ & $5(0.8 \%)$ & & $6(1.1 \%)$ & $2(0.4 \%)$ & \\
\hline Metabolic & $0(0.0 \%)$ & $0(0.0 \%)$ & & $0(0.0 \%)$ & $0(0.0 \%)$ & & $1(0.2 \%)$ & $1(0.2 \%)$ & & $1(0.2 \%)$ & $3(0.56 \%)$ & \\
\hline Other medical admissions & $4(0.6 \%)$ & $5(0.8 \%)$ & & $4(0.7 \%)$ & $9(1.7 \%)$ & & $26(4.3 \%)$ & $29(4.5 \%)$ & & $35(6.5 \%)$ & $29(5.5 \%)$ & \\
\hline
\end{tabular}

Definition of abbreviations: APACHE = Acute Physiology and Chronic Health Evaluation; BMI = body mass index; EPaNIC = Early Parenteral Nutrition to Supplement Insufficient Enteral Nutrition in Intensive Care; IQR = interquartile range; NRS = Nutritional Risk Screening; PN = parenteral.

variable. We therefore analyzed the association between increasing cumulative doses of glucose as compared with protein/amino acid and the likelihood for earlier "alive-discharge from the ICU" in one adjusted proportional hazards analysis on Days 3, 5, and 7. To allow comparison between the relative associative effect of increasing cumulative glucose and protein/amino acid doses in one proportional hazards model, they were normalized to a percentage of target. This target was based on the amount of glucose and protein/amino acid the patient would have received when receiving $100 \%$ of calculated energy by standard commercial PN preparation (OliClinomel-N7; Baxter). The relationship between glucose intake on Day 1 and recovery was analyzed independent of protein/amino acid dose because on this day, according to protocol, virtually no protein had been administered.

All analyses were performed with JMP (version 7; SAS Institute Inc., Cary, NC). Partial residuals and log-minus-log plots were analyzed in SPSS statistics 19 (IBM, Chicago, IL).

\section{RESULTS}

\section{Effect of Early PN versus Late PN in Subgroups of Patients with Increasing Severity of Illness}

Dividing the total EPaNIC population into quartiles of (ordinal) APACHE II scores yielded four large subgroups (Table 1 and Figure 1A; and see Table E1 in the online supplement). Proportional hazards analysis showed no significant interaction (interaction $P=0.296$ ) (Table E2) between randomization and these APACHE II quartiles.

The 1,822 "other patients" were more severely ill on ICU admission, resulting in fewer patients in the first and second APACHE quartiles (Table 2, Figure 1B, and Table E1). Also in this population, no significant interaction between randomization and APACHE II quartiles was detected $(P=0.250)$ (Table E2).

The OR for alive ICU discharge within 8 days in logistic regression analysis revealed no benefit from early $\mathrm{PN}$ in any of the quartiles of disease severity (Table E3).

The beneficial effect of late PN on acquisition of a new infection in the total EPaNIC population was generalizable to all APACHE II quartiles (interaction $P=0.525$ ). The proportion of patients acquiring new infection was reduced from 16.9 to $12.6 \%$ in the second quartile and from 36.8 to $30.1 \%$ in the third quartile (Figure 1C). In the "other patients" population, again, no interaction was detected $(P=0.795)$ (Figure 1D and Table E2).

\section{Association between Dose of Macronutrients and Recovery from Critical Illness}

In both groups, approximately $90 \%$ of the patients still present in the ICU on days of interest did not achieve minimal nutrition by mouth and thus were included in the analysis (Table 3). During the first week, patients in the early-PN group received a mean $1,576 \pm 368 \mathrm{kcal} /$ day versus $594 \pm 345 \mathrm{kcal} /$ day in the late-PN group. On all analyzed days, an inverse relation between the "cumulative energy intake received up to the day of analysis," analyzed as a continuous variable, and the likelihood of an earlier alive-discharge from the ICU in the following days was found ( $P$ values; Figure 2$)$, in both the early-PN and late-PN groups. A $1 \%$ increase in percentage of caloric target per day was associated with a $0.2 \%$ to $0.8 \%$ decrease in likelihood for earlier alive-discharge from the ICU (Table E4).

Analysis of cumulative energy intervals revealed a reduced likelihood for earlier alive-discharge from the ICU with increasing energy intake (Figure 2). This inverse relation appeared linear and progressive over the energy intake range in the early-PN group and in the total population (Figure 2). Logistic regression analysis of alive-discharge from the ICU within 8 days revealed a similar relation (Table E5). Kaplan-Meier plots showed that the proportion of patients discharged alive from the ICU from any of the analyzed days onward, was lower with the highest and higher with the lowest cumulative energy intake (Figure E1).

Data for Days 10 and 14 were comparable to Days 3, 5, and 7, but numbers of patients per group were much smaller. Splittingrelated artifacts were excluded on the basis of similar results obtained by proportional hazards analyses with the second set of energy intervals (data not shown).

\section{Association between Glucose Dose versus Protein/Amino Acid Dose and Recovery from Critical Illness}

On Day 7, in the early-PN group, the mean cumulative glucose and protein/amino acid dose were $204.2( \pm 46.7) \mathrm{g} /$ day and 47.2 
TABLE 2. DEMOGRAPHICS OF PATIENTS IN QUARTILES BASED ON ADMISSION APACHE II SCORE: OTHER PATIENTS (NOT ADMITTED AFTER CARDIAC SURGERY)

\begin{tabular}{|c|c|c|c|c|c|c|c|c|c|c|c|c|}
\hline & \multicolumn{3}{|c|}{ APACHE Quartile I: 13 (10-14) } & \multicolumn{3}{|c|}{ APACHE Quartile II: 17 (16-18) } & \multicolumn{3}{|c|}{ APACHE Quartile III: 28 (24-30) } & \multicolumn{3}{|c|}{ APACHE Quartile IV: 37 (35-41) } \\
\hline & Early PN & Late PN & $P$ Value & Early PN & Late PN & $P$ Value & Early PN & Late PN & $P$ Value & Early PN & Late PN & $P$ Value \\
\hline $\mathrm{n}$ & 70 & 64 & & 63 & 70 & & 334 & 348 & & 435 & 438 & \\
\hline Age, yr & $54.0( \pm 14.5)$ & $52.3( \pm 19.2)$ & 0.28 & $63.1( \pm 10.6)$ & $62.8( \pm 14.5)$ & 0.45 & $55.5( \pm 16.1)$ & $55.6( \pm 17.8)$ & 0.50 & $63.9( \pm 13.4)$ & $63.5( \pm 14.1)$ & 0.34 \\
\hline BMI, mean $( \pm S D)$ & $25.8( \pm 4.8)$ & $25.6( \pm 5.3)$ & 0.38 & $25.7( \pm 6.0)$ & $25.3( \pm 5.9)$ & 0.36 & $26.0( \pm 5.3)$ & $25.3( \pm 5.0)$ & 0.039 & $25.8( \pm 5.9)$ & $25.8( \pm 5.3)$ & 0.48 \\
\hline NRS, median (IQR) & $3(3-4)$ & $3(3-4)$ & 0.84 & $3(3-5)$ & $4(3-5)$ & 0.63 & $3(3-5)$ & $3(3-5)$ & 0.84 & $4(3-5)$ & $4(3-5)$ & 0.29 \\
\hline Cancer, n (\%) & $40(57.1 \%)$ & $29(45.3 \%)$ & 0.22 & $30(47.6 \%)$ & $36(51.4 \%)$ & 0.72 & $77(23.1 \%)$ & $96(27.6 \%)$ & 0.187 & $147(33.8 \%)$ & $124(28.3 \%)$ & 0.092 \\
\hline Diagnostic category on admission, $\mathrm{n}(\%)$ & & & 0.20 & & & 0.27 & & & 0.97 & & & 0.81 \\
\hline \multicolumn{13}{|l|}{ Surgical admissions } \\
\hline Cardiac surgery & $0(0.0 \%)$ & $0(0.0 \%)$ & & $0(0.0 \%)$ & $0(0.0 \%)$ & & $0(0.0 \%)$ & $0(0.0 \%)$ & & $0(0.0 \%)$ & $0(0.0 \%)$ & \\
\hline Complicated abdominal or pelvic surgery & $33(47.1 \%)$ & $20(31.3 \%)$ & & $18(28.6 \%)$ & $27(38.6 \%)$ & & $49(14.7 \%)$ & $45(17.0 \%)$ & & $70(16.1 \%)$ & $72(16.4 \%)$ & \\
\hline Transplantation & $1(1.4 \%)$ & $0(0.0 \%)$ & & $1(1.6 \%)$ & $0(0.0 \%)$ & & $45(13.5 \%)$ & $42(12.1 \%)$ & & $118(27.1 \%)$ & $121(27.6 \%)$ & \\
\hline Trauma: burns or reconstructive surgery & $2(2.9 \%)$ & $6(9.4 \%)$ & & $7(11.1 \%)$ & $6(8.6 \%)$ & & $66(19.8 \%)$ & $64(18.4 \%)$ & & $24(5.5 \%)$ & $31(7.1 \%)$ & \\
\hline Complicated thoracic surgery & $16(22.9 \%)$ & $17(26.6 \%)$ & & $14(22.2 \%)$ & $11(15.7 \%)$ & & $25(7.5 \%)$ & $25(7.2 \%)$ & & $31(7.1 \%)$ & $30(6.9 \%)$ & \\
\hline Complicated vascular surgery & $8(11.4 \%)$ & $13(20.3 \%)$ & & $15(23.8 \%)$ & $9(12.9 \%)$ & & $18(5.4 \%)$ & $15(4.3 \%)$ & & $24(5.5 \%)$ & $32(7.3 \%)$ & \\
\hline Complicated neurosurgery & $3(4.3 \%)$ & $0(0.0 \%)$ & & $1(1.6 \%)$ & $0(0.0 \%)$ & & $39(11.7 \%)$ & $40(11.5 \%)$ & & $18(4.1 \%)$ & $14(3.2 \%)$ & \\
\hline Neurological disease & $0(0.0 \%)$ & $0(0.0 \%)$ & & $0(0.0 \%)$ & $0(0.0 \%)$ & & $10(3.0 \%)$ & $14(4.0 \%)$ & & $4(0.9 \%)$ & $1(0.2 \%)$ & \\
\hline \multicolumn{13}{|l|}{ Medical admissions } \\
\hline Respiratory & $1(1.4 \%)$ & $2(3.13 \%)$ & & $1(1.6 \%)$ & $3(4.29 \%)$ & & $24(7.2 \%)$ & $24(6.9 \%)$ & & $46(10.6 \%)$ & $42(9.6 \%)$ & \\
\hline Gastroenterologic or hepatic & $2(2.9 \%)$ & $1(1.6 \%)$ & & $1(1.6 \%)$ & $4(5.7)$ & & $20(6.0 \%)$ & $21(6.0 \%)$ & & $32(7.4 \%)$ & $35(8.0 \%)$ & \\
\hline Hematological or oncological & $0(0.0 \%)$ & $0(0.0 \%)$ & & $0(0.0 \%)$ & $1(1.4 \%)$ & & $5(1.5 \%)$ & $4(1.2 \%)$ & & $13(3.0 \%)$ & $11(2.5 \%)$ & \\
\hline Cardiovascular & $0(0.0 \%)$ & $0(0.0 \%)$ & & $0(0.0 \%)$ & $0(0.0 \%)$ & & $3(0.9 \%)$ & $2(0.6 \%)$ & & $5(1.2 \%)$ & $8(1.8 \%)$ & \\
\hline Renal & $0(0.0 \%)$ & $0(0.0 \%)$ & & $0(0.0 \%)$ & $0(0.0 \%)$ & & $0(0.0 \%)$ & $3(0.9 \%)$ & & $8(1.8 \%)$ & $7(1.6 \%)$ & \\
\hline Neurological & $0(0.0 \%)$ & $0(0.0 \%)$ & & $1(1.6 \%)$ & $0(0.0 \%)$ & & $3(0.9 \%)$ & $5(1.4 \%)$ & & $6(1.4 \%)$ & $2(0.5 \%)$ & \\
\hline Metabolic & $0(0.0 \%)$ & $0(0.0 \%)$ & & $0(0.0 \%)$ & $0(0.0 \%)$ & & $1(0.3 \%)$ & $1(0.3 \%)$ & & $1(0.2 \%)$ & $3(0.7 \%)$ & \\
\hline Other medical admissions & $4(5.7 \%)$ & $5(7.8 \%)$ & & $4(0.7 \%)$ & $9(12.9 \%)$ & & $26(7.8 \%)$ & $29(8.3 \%)$ & & $35(8.1 \%)$ & $29(6.6 \%)$ & \\
\hline
\end{tabular}

Definition of abbreviations: APACHE = Acute Physiology and Chronic Health Evaluation; BMI = body mass index; IQR = interquartile range; NRS = Nutritional Risk Screening; $\mathrm{PN}=$ parenteral.

$( \pm 15.1) \mathrm{g} /$ day, respectively, as compared with only $91.8( \pm 44.3) \mathrm{g} /$ day and $14.2( \pm 14.6) \mathrm{g} /$ day in the late-PN group.

Glucose dose on ICU Day 1 was neutrally related to the likelihood of an earlier alive-discharge from the ICU thereafter (hazard ratio, 0.87; confidence interval, 0.695-1.108). On Days 3, 5, and 7 , the relative association of increasing cumulative glucose intake, as compared with protein/amino acid intake, with the likelihood of an earlier alive-discharge from the ICU, was never in favor of protein/amino acid (Figure 3).

\section{Testing the Proportional Hazards Assumption}

The log-minus-log plot for early PN versus late PN in the proportional hazards model revealed no time dependency (Figure E2). For patients still in the ICU on Day 3, the partial residual plot for cumulative energy on Day 3 suggested time dependency, which was confirmed by incorporating the time-dependent variable in the proportional hazards model. The inverse relationship between energy intake and likelihood of an earlier alive-discharge from the ICU was then even slightly more

TABLE 3. DEMOGRAPHICS OF PATIENTS IN CUMULATIVE ENERGY ANALYSES

\begin{tabular}{|c|c|c|c|c|c|c|c|c|c|}
\hline & \multicolumn{3}{|c|}{ Patients Analyzed on ICU Day 3} & \multicolumn{3}{|c|}{ Patients Analyzed on ICU Day 5} & \multicolumn{3}{|c|}{ Patients Analyzed on ICU Day 7} \\
\hline & Early PN & Late PN & $P$ Value & Early PN & Late PN & $P$ Value & Early PN & Late PN & $P$ Value \\
\hline $\mathrm{n}$ & 1358 & 1312 & & 893 & 823 & & 677 & 585 & \\
\hline Age, yr & $64.4( \pm 14.5)$ & $64.3( \pm 15.4)$ & 0.37 & $63.4(14.8)$ & $63.2( \pm 15.8)$ & 0.40 & $62.7( \pm 14.9)$ & $62.8( \pm 16.1)$ & 0.51 \\
\hline BMI, mean ( $\pm S D)$ & $26.5( \pm 5.3)$ & $26.2( \pm 4.9)$ & 0.07 & $26.3( \pm 5.5)$ & $26.1( \pm 5.1)$ & 0.22 & $26.3( \pm 5.3)$ & $26.2( \pm 5.3)$ & 0.339 \\
\hline NRS, median (IQR) & $3(4-4)$ & $3(4-5)$ & 0.44 & $3(4-5)$ & $3(4-5)$ & 0.58 & $4(3-5)$ & $4(3-5)$ & 0.66 \\
\hline APACHE II score, median (IQR) & $27(17-35)$ & $27(17-35)$ & 0.68 & $31(22-37)$ & $31(22-37)$ & 0.75 & $32(24-38)$ & $33(25-38)$ & 0.199 \\
\hline Cancer, n (\%) & $296(21.8 \%)$ & $288(22.0 \%)$ & 0.92 & $224(25.1 \%)$ & $187(22.7 \%)$ & 0.25 & $166(24.5 \%)$ & $145(24.8 \%)$ & 0.94 \\
\hline Diagnostic category on admission & & & 0.98 & & & 0.31 & & & 0.99 \\
\hline \multicolumn{10}{|l|}{ Surgical admissions, n (\%) } \\
\hline Cardiac surgery & $627(46.2 \%)$ & $614(46.8 \%)$ & & $321(36.0 \%)$ & $287(34.9 \%)$ & & $206(30.4 \%)$ & $166(28.4 \%)$ & \\
\hline Complicated abdominal or pelvic surgery & $125(9.2 \%)$ & $119(9.1 \%)$ & & $97(10.9 \%)$ & $93(11.3 \%)$ & & $83(12.3 \%)$ & $77(13.2 \%)$ & \\
\hline Transplantation & $131(9.7 \%)$ & $120(9.2 \%)$ & & $86(9.6 \%)$ & $79(9.6 \%)$ & & $61(9.0 \%)$ & $49(8.4 \%)$ & \\
\hline Trauma: burns or reconstructive surgery & $88(6.5 \%)$ & $96(7.3 \%)$ & & $78(8.7 \%)$ & $78(9.5 \%)$ & & $69(10.2 \%)$ & $65(11.1 \%)$ & \\
\hline Complicated thoracic surgery & $67(4.9 \%)$ & $59(4.5 \%)$ & & $56(6.3 \%)$ & $52(6.3 \%)$ & & $45(6.7 \%)$ & $43(7.4 \%)$ & \\
\hline Complicated vascular surgery & $47(3.5 \%)$ & $48(3.7 \%)$ & & $31(3.5 \%)$ & $39(4.7 \%)$ & & $30(4.4 \%)$ & $33(5.6 \%)$ & \\
\hline Complicated neurosurgery & $52(3.8 \%)$ & $43(3.3 \%)$ & & $40(4.5 \%)$ & $34(4.1 \%)$ & & $34(5.0 \%)$ & $27(4.6 \%)$ & \\
\hline Neurological disease & $12(0.9 \%)$ & $10(0.8 \%)$ & & $9(1.0 \%)$ & $8(1.0 \%)$ & & $7(1.0 \%)$ & $4(0.7 \%)$ & \\
\hline \multicolumn{10}{|l|}{ Medical admissions, n (\%) } \\
\hline Respiratory & $62(4.6 \%)$ & $58(4.4 \%)$ & & $49(5.5 \%)$ & $39(4.7 \%)$ & & $38(5.6 \%)$ & $32(5.5 \%)$ & \\
\hline Gastroenterologic or hepatic & $48(3.5 \%)$ & $50(3.8 \%)$ & & $41(4.6 \%)$ & $39(4.7 \%)$ & & $36(5.3 \%)$ & $31(5.3 \%)$ & \\
\hline Hematological or oncological & $17(1.3 \%)$ & $13(1 \%)$ & & $16(1.8 \%)$ & $12(1.5 \%)$ & & $12(1.8 \%)$ & $12(2.1 \%)$ & \\
\hline Cardiovascular & $5(0.4 \%)$ & $9(0.7 \%)$ & & $5(0.6 \%)$ & $6(0.7 \%)$ & & $5(0.7 \%)$ & $5(0.9 \%)$ & \\
\hline Renal & $8(0.6 \%)$ & $7(0.5 \%)$ & & $7(0.8 \%)$ & $5(0.6 \%)$ & & $6(0.9 \%)$ & $5(0.9 \%)$ & \\
\hline Neurological & $10(0.7 \%)$ & $7(0.5 \%)$ & & $9(1.0 \%)$ & $5(0.6 \%)$ & & $5(0.7 \%)$ & $3(0.5 \%)$ & \\
\hline Metabolic & $1(0.1 \%)$ & $3(0.2 \%)$ & & $1(0.1 \%)$ & $3(0.2 \%)$ & & $1(0.2 \%)$ & $0(0.0 \%)$ & \\
\hline Other medical admissions & $58(4.3 \%)$ & $56(4.3 \%)$ & & $47(5.3 \%)$ & $44(5.4 \%)$ & & $39(4.8 \%)$ & $33(5.6 \%)$ & \\
\hline
\end{tabular}

Definition of abbreviations: $\mathrm{BMI}=$ body mass index; ICU = intensive care unit; IQR = interquartile range; NRS = Nutritional Risk Screening; PN = parenteral. 
Early PN

( $\mathrm{N}$ on day $1=2312$ )

$N$ analyzed $=1358 / 1438$

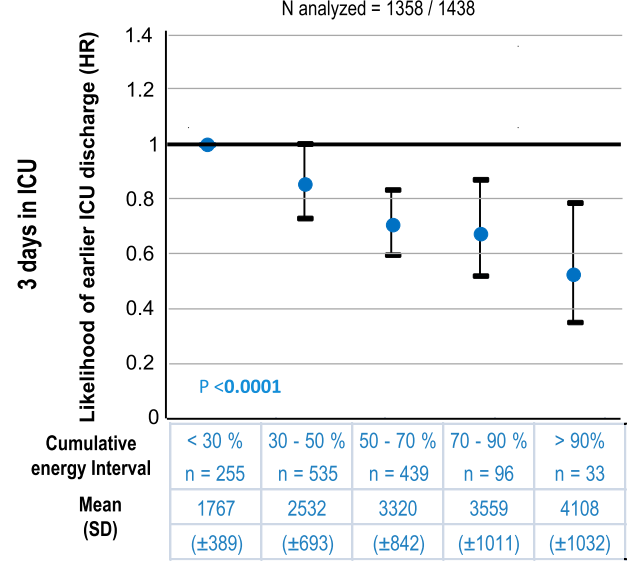

$\mathrm{N}$ analyzed $=893 / 975$
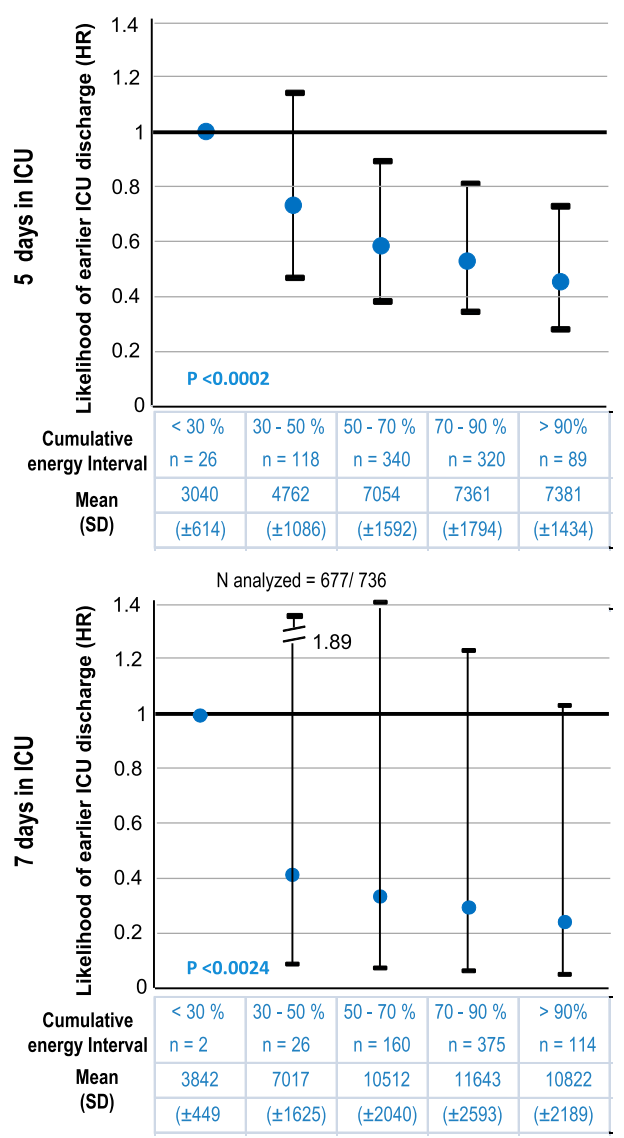

Total Population

( $\mathrm{N}$ on day $1=4640$ )
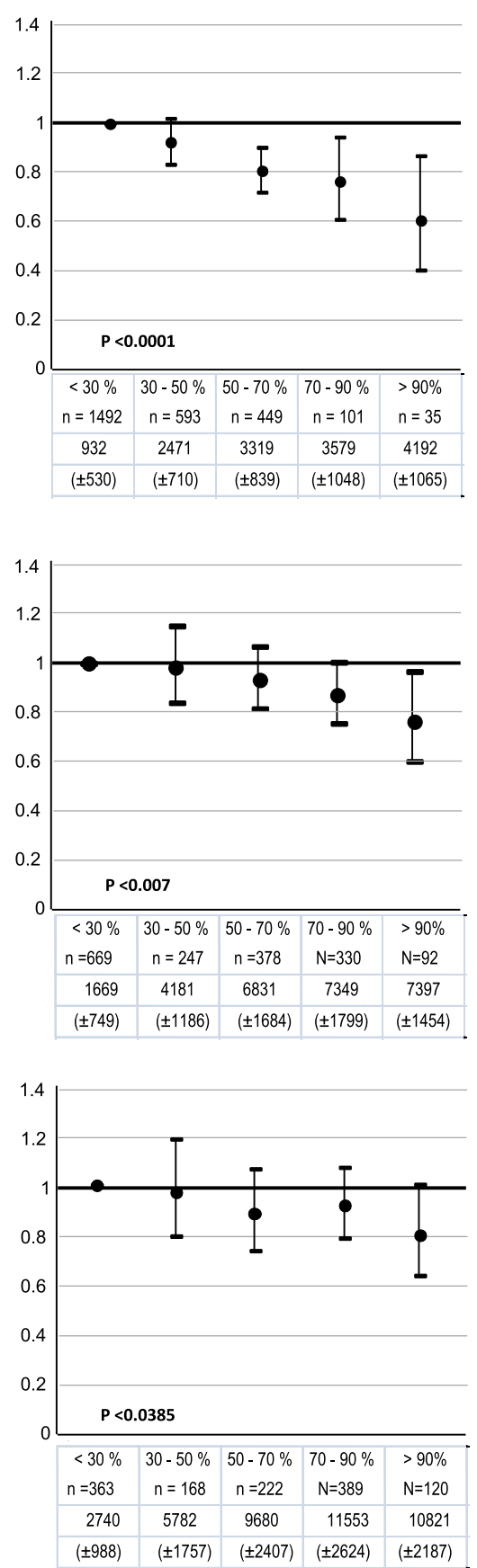

Late PN

( $\mathrm{N}$ on day $1=2328$ )

$N$ analyzed $=1312 / 1399$

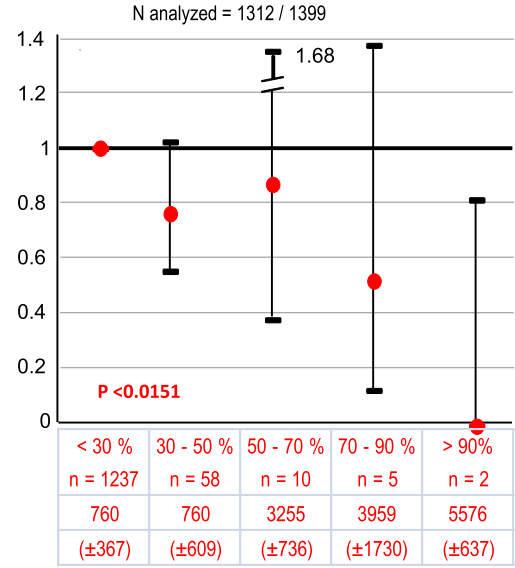

$\mathrm{N}$ analyzed $=823 / 913$
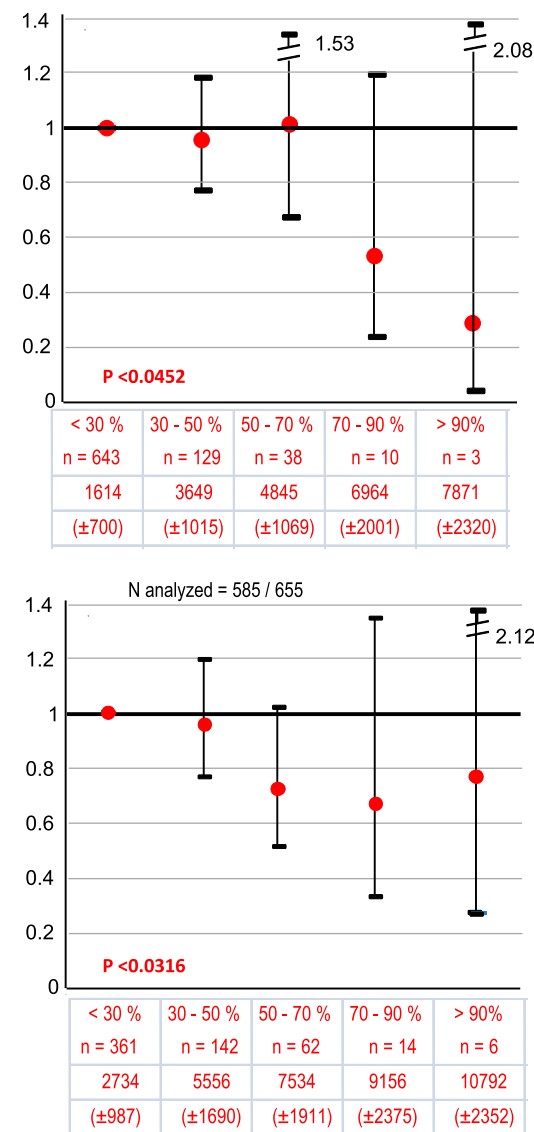

Figure 2. Chance of an earlier live discharge from the intensive care unit (ICU) with increasing nutrition doses. Analyzes within early parenteral (early-PN) group (left), total population (middle), and late-PN group (right) for patients still in the ICU and not receiving adequate oral nutrition on Day 3 (top), Day 5 (middle), and Day 7 (bottom). Numbers above the graphs are as follows: number of patients analyzed/number of patients still in ICU on analysis day. $P$ values in boldface: significance level of the association between likelihood for an earlier discharge alive from the ICU and increased cumulative energy intake until the day of analysis, analyzed continuously in an adjusted Cox proportional hazards model. For hazard ratios (HRs) and confidence intervals (Cls) per 1\% increase of target per day reached, please refer to Table E4. Graphs: Hazard ratios and confidence intervals for an earlier live discharge from the ICU are displayed for every cumulative energy interval as compared with the lowest interval (reference $=1)$. Numbers below the graphs: number of patients per interval $(n)$, cumulative energy (protein included) in mean kilocalories ( \pm standard deviation) in the interval. Note the small numbers in the highest energy intervals in the late-PN group on Days 3, 5, and 7 and in the lowest energy interval in the early-PN group on Day 7; these HRs and Cls should be interpreted with caution. Whereas Kaplan-Meier curves (Figure E1) depict only the first 30 days in ICU, the hazard ratios, in contrast, are based on every patient's entire ICU stay starting on the analysis day. 


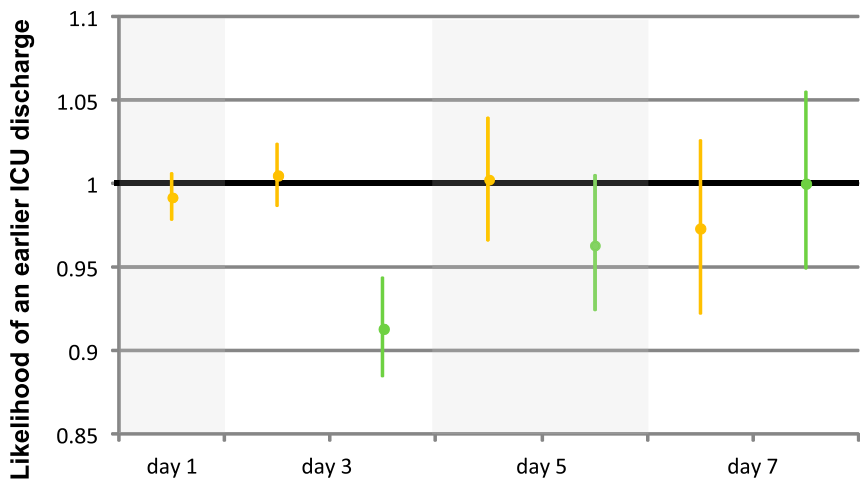

Figure 3. Time to live discharge from the intensive care unit (ICU): Relation to glucose dose as compared with protein dose. Effect size per $10 \%$ increments of target per day in cumulative glucose intake $(\sim \pm 28 \mathrm{~g} / \mathrm{d})$ (yellow) and cumulative protein intake ( $\sim \pm 7 \mathrm{~g} / \mathrm{d}$ ) (green) in a time-to-alive ICU discharge analysis corrected for severity and type of disease. Normalized glucose target was $276.4( \pm 70.8) \mathrm{g} /$ day and normalized protein target was $72.3( \pm 18.5) \mathrm{g} /$ day. This target was derived from the amount of glucose and protein the patient would have received with the standard commercial parenteral (PN) preparation when receiving $100 \%$ of his calculated energy target.

pronounced (hazard ratio, 0.995; confidence interval, 0.9930.997).

\section{DISCUSSION}

This post hoc, in-depth secondary analysis of prospectively collected data from the EPaNIC trial did not support the hypothesis that the observed deleterious impact of early PN on recovery from critical illness would be limited to the less severely ill patients. Also, the negative impact of early $\mathrm{PN}$ on recovery was not explained by the dose of macronutrients. No intermediate dose, as compared with the lowest dose, was associated with improved outcome. Finally, our analyses revealed no indication that the predominance of glucose over protein/amino acids would explain the deleterious effects evoked by early PN.

The beneficial effect of late PN was generalized across different strata of severity of illness as no interaction between randomization and APACHE II quartiles was found. Thus, patients who are more severely ill, intuitively assumed to benefit most from early PN, in fact do not. This lack of benefit with early PN, although at first sight surprising, is in line with the paucity of evidence in favor of PN. Results from meta-analyses of PN versus EN are conflicting (18-20). Increased enteral and parenteral intake, through indirect calorimetry-guided nutrition, resulted in more morbidity, but a trend for lower mortality as compared with fixed-target feeding (21). In 230 major surgery or trauma patients early $\mathrm{PN}$, as compared with parenteral glucose $5 \%$ for up to 14 days, did not affect mortality (22). Also, randomization to $\mathrm{PN}$ rather than EN when clinicians were unsure about gastrointestinal adequacy was not beneficial (23). Results from a small study, completed in 2010 , are today only partially available in abstract. They suggest reduced incidence of new infections but similar length of ICU stay with early PN (Day 4) as compared with late PN (Day 8) in a highly selected group of patients (24). In observational studies, early PN plus EN improved nutritional intake but not outcome (25).

The lowest cumulative caloric dose interval, far below the recommended $20-30 \mathrm{kcal} \cdot \mathrm{kg}^{-1} \cdot \mathrm{day}^{-1}(26)$, was associated with similar or better outcome than any of the higher doses (Figure 2 ). In the early-PN population, the likelihood for earlier alivedischarge from the ICU clearly declined significantly from the third energy interval onward. This interval corresponds to an average nonprotein intake of $13-18 \mathrm{kcal} \cdot \mathrm{kg}^{-1} \cdot \mathrm{day}^{-1}$, amounts of nutrition never considered to be excessive. Surprisingly, also in the late-PN group, patients receiving more (enteral) nutrition during the first week did not recover faster. Although based on a smaller number of patients, these data might suggest that, irrespective of the route of feeding, the concept of maximizing nutritional intake should be revisited. Rice and colleagues reported unaffected morbidity and mortality despite important cumulative energy debt with "trickle enteral feeding" as compared with full enteral feeding in 1,000 patients with respiratory failure (27). Ibrahim and colleagues observed even better outcomes with less aggressive feeding (12). In two large cluster randomized studies, the guidelines for optimal feeding improved nutrition delivery, but this improved outcome only in the first trial $(28,29)$. Observational data, in contrast, generally support the practice of early adequate feeding $(13,30,31)$. Analyzing nutrition intake while comparing different durations of ICU stay, however, is complicated and often methodologically flawed. During ICU stay, daily caloric intake tends to increase progressively to approach target, but the cumulative energy debt usually persists or increases. Bias evoked by time in ICU could explain the contrasting results of previous observational trials $(11,13,30,31)$. Clearly, sufficiently powered randomized controlled trials with strong clinical end points comparing different energy doses are needed. On the basis of Rice's and our data, it appears unlikely that promoting aggressive enteral or parenteral feeding during the first week of critical illness is beneficial (32).

Finally, the predominance of glucose over protein/amino acids in the early-PN strategy did not seem to explain the deleterious effects evoked by early PN. Lipogenesis occurs when glucose intake exceeds $4 \mathrm{mg} \cdot \mathrm{kg}^{-1} \cdot$ minute $^{-1}\left(\sim 5.7 \mathrm{~g} \cdot \mathrm{kg}^{-1} \cdot\right.$ day $\left.^{-1}\right)$ $(14,33)$. In the early-PN arm of the EPaNIC trial, however, the total daily glucose doses were much lower (mean, $3.3[ \pm 1.3] \mathrm{g} \cdot \mathrm{kg}^{-1} \cdot \mathrm{d}^{-1}$ even on Day 7) (3). The cumulative protein/amino acid dose, rather than the cumulative glucose dose, early during ICU stay was associated with delayed recovery. This apparent absence of a beneficial outcome with more protein intake may not be that surprising, given the lack of evidence supporting the recommended protein doses. Although increased amino acid intake may improve nitrogen balances (34-37), it never improved outcome $(38,39)$ and it may increase oxidative burden (36).

Our results suggest that, irrespective of the route of administration, the amount of macronutrients administered early during critical illness may worsen outcome. Enhanced autophagy by nutrient restriction for 1 week may be one of the underlying mechanisms. Autophagy is a cellular housekeeping system clearing damaged organelles and toxic protein aggregates to preserve cell integrity $(40,41)$. In critically ill rabbits fasting as compared with early nutrition, resulted in catabolism but also in functional autophagy, better maintained cell integrity and protected organ function (42).

Our study has some limitations. While the first part of this analysis is based on the randomized intervention in the intention-to-treat population in strata by prerandomization characteristics, the energy dose and macronutrient analyses are based on a posteriori association within subgroups of patients defined by length of stay. All results of these post hoc analyses must be interpreted as hypothesis-generating. Nevertheless, the unequivocal results of the uncorrected Kaplan-Meier plots and of the adjusted proportional hazards models, crude proportions of patients and multivariable logistic regression analyses, within the total population, the early-PN and late-PN groups support the robustness of our observational findings. 
In conclusion, no subpopulation of critically ill patients could be identified that benefited from early PN. In a context of adequate micronutrient substitution to all patients, the benefit of late PN appears general across the entire range of severity of illness. Our data also suggest that caloric targets currently recommended by international guidelines may be inappropriate for the first week of critical illness and should be revised. Finally, the claimed benefit of higher protein doses early in critical illness was not substantiated by the results of this study.

Author disclosures are available with the text of this article at www.atsjournals.org.

Acknowledgment: The authors acknowledge all the authors and collaborators in the original EPaNIC trial for the opportunity to perform this analysis.

\section{References}

1. Jeevanandam M, Young DH, Schiller WR. Influence of parenteral nutrition on rates of net substrate oxidation in severe trauma patients. Crit Care Med 1990;18:467-473.

2. Doig GS, Simpson F, Sweetman EA. Evidence-based nutrition support in the intensive care unit: an update on reported trial quality. Curr Opin Clin Nutr Metab Care 2009;12:201-206.

3. Casaer MP, Mesotten D, Hermans G, Wouters PJ, Schetz M, Meyfroidt G, Van CS, Ingels C, Meersseman P, Muller J, et al. Early versus late parenteral nutrition in critically ill adults. N Engl J Med 2011;365:506517.

4. Singer P, Berger MM, Van den Berghe G, Biolo G, Calder P, Forbes A, Griffiths R, Kreyman G, Leverve X, Pichard C, et al. ESPEN guidelines on parenteral nutrition: intensive care. Clin Nutr 2009;28: 387-400.

5. Martindale RG, Mcclave SA, Vanek VW, McCarthy M, Roberts P, Taylor B, Ochoa JB, Napolitano L, Cresci G. Guidelines for the provision and assessment of nutrition support therapy in the adult critically ill patient: Society of Critical Care Medicine and American Society for Parenteral and Enteral Nutrition [Executive Summary]. Crit Care Med 2009;37:1757-1761.

6. Vanderheyden S, Casaer MP, Kesteloot K, Simoens S, De RT, Peers G, Wouters PJ, Coenegrachts J, Grieten T, Polders K, et al. Early versus late parenteral nutrition in ICU patients: cost analysis of the EPaNIC trial. Crit Care 2012;16:R96.

7. Casaer MP, Hermans G, Wilmer A, Van den Berghe G. Impact of early parenteral nutrition completing enteral nutrition in adult critically ill patients (EPaNIC trial): a study protocol and statistical analysis plan for a randomized controlled trial. Trials 2011;12:21.

8. O'Leary MJ, Ferrie S. Early or late parenteral nutrition in critically ill adults [letter]. N Engl J Med 2011;365:1839-1840; author reply 18411842

9. Felbinger TW, Weigand MA, Mayer K. Early or late parenteral nutrition in critically ill adults [letter]. N Engl J Med 2011;365:1839; author reply $1841-1842$

10. Heyland DK; ACP Journal Club. Late initiation of parenteral nutrition reduced length of intensive care unit stay. Ann Intern Med 2011;155: JC5-JC11.

11. Krishnan JA, Parce PB, Martinez A, Diette GB, Brower RG. Caloric intake in medical ICU patients: consistency of care with guidelines and relationship to clinical outcomes. Chest 2003;124: 297-305.

12. Ibrahim EH, Mehringer L, Prentice D, Sherman G, Schaiff R, Fraser V, Kollef MH. Early versus late enteral feeding of mechanically ventilated patients: results of a clinical trial. JPEN J Parenter Enteral Nutr 2002;26:174-181.

13. Alberda C, Gramlich L, Jones N, Jeejeebhoy K, Day AG, Dhaliwal R, Heyland DK. The relationship between nutritional intake and clinical outcomes in critically ill patients: results of an international multicenter observational study. Intensive Care Med 2009;35:17281737

14. Bistrian BR. Early or late parenteral nutrition in critically ill adults. $N$ Engl J Med 2011;365:1840-1842.
15. Knaus WA, Draper EA, Wagner DP, Zimmerman JE. APACHE II: a severity of disease classification system. Crit Care Med 1985;13:818829

16. Andersen PK, Abildstrom SZ, Rosthoj S. Competing risks as a multistate model. Stat Methods Med Res 2002;11:203-215.

17. Kondrup J, Allison SP, Elia M, Vellas B, Plauth M. ESPEN guidelines for nutrition screening 2002. Clin Nutr 2003;22:415-421.

18. Simpson F, Doig GS. Parenteral vs. enteral nutrition in the critically ill patient: a meta-analysis of trials using the intention to treat principle. Intensive Care Med 2005;31:12-23.

19. Heyland DK, MacDonald S, Keefe L, Drover JW. Total parenteral nutrition in the critically ill patient: a meta-analysis. JAMA 1998;280: 2013-2019.

20. Dhaliwal R, Jurewitsch B, Harrietha D, Heyland DK. Combination enteral and parenteral nutrition in critically ill patients: harmful or beneficial? A systematic review of the evidence. Intensive Care Med 2004;30:1666-1671.

21. Singer P, Anbar R, Cohen J, Shapiro H, Shalita-Chesner M, Lev S, Grozovski E, Theilla M, Frishman S, Madar Z. The Tight Calorie Control Study (TICACOS): a prospective, randomized, controlled pilot study of nutritional support in critically ill patients. Intensive Care Med 2011;37:601-609.

22. Sandstrom R, Drott C, Hyltander A, Arfvidsson B, Schersten T, Wickstrom I, Lundholm K. The effect of postoperative intravenous feeding (TPN) on outcome following major surgery evaluated in a randomized study. Ann Surg 1993;217:185-195.

23. Woodcock NP, Zeigler D, Palmer MD, Buckley P, Mitchell CJ, MacFie J. Enteral versus parenteral nutrition: a pragmatic study. Nutrition 2001; 17:1-12.

24. Heidegger CP, Graf S, Thibault R, Darmon P, Berger M, Pichard C. Supplemental parenteral nutrition (SPN) in intensive care unit (ICU) patients for optimal energy coverage: improved clinical outcome [abstract]. Clin Nutr 2011;6:1-2.

25. Cahill NE, Murch L, Jeejeebhoy K, McClave SA, Day AG, Wang M, Heyland DK. When early enteral feeding is not possible in critically ill patients: results of a multicenter observational study. JPEN J Parenter Enteral Nutr 2011;35:160-168.

26. Kreymann KG, Berger MM, Deutz NE, Hiesmayr M, Jolliet P, Kazandjiev G, Nitenberg G, Van den Berghe G, Wernerman J, Ebner $\mathrm{C}$, et al. ESPEN guidelines on enteral nutrition: intensive care. Clin Nutr 2006;25:210-223.

27. Rice TW, Wheeler AP, Thompson BT, Steingrub J, Hite RD, Moss M, Morris A, Dong N, Rock P. Initial trophic vs full enteral feeding in patients with acute lung injury: the EDEN randomized trial. $J A M A$ 2012;307:795-803

28. Martin CM, Doig GS, Heyland DK, Morrison T, Sibbald WJ. Multicentre, cluster-randomized clinical trial of algorithms for critical-care enteral and parenteral therapy (ACCEPT). CMAJ 2004;170:197204

29. Doig GS, Simpson F, Finfer S, Delaney A, Davies AR, Mitchell I, Dobb G. Effect of evidence-based feeding guidelines on mortality of critically ill adults: a cluster randomized controlled trial. JAMA 2008;300: 2731-2741.

30. Dvir D, Cohen J, Singer P. Computerized energy balance and complications in critically ill patients: an observational study. Clin Nutr 2006; 25:37-44.

31. Villet S, Chiolero RL, Bollmann MD, Revelly JP, Cayeux RNM, Delarue J, Berger MM. Negative impact of hypocaloric feeding and energy balance on clinical outcome in ICU patients. Clin Nutr 2005; 24:502-509.

32. Ridley EJ, Davies AR. Practicalities of nutrition support in the intensive care unit: the usefulness of gastric residual volume and prokinetic agents with enteral nutrition. Nutrition 2011;27:509-512.

33. Guenst JM, Nelson LD. Predictors of total parenteral nutrition-induced lipogenesis. Chest 1994;105:553-559.

34. Scheinkestel CD, Adams F, Mahony L, Bailey M, Davies AR, Nyulasi I, Tuxen DV. Impact of increasing parenteral protein loads on amino acid levels and balance in critically ill anuric patients on continuous renal replacement therapy. Nutrition 2003;19:733-740.

35. Singer P. High-dose amino acid infusion preserves diuresis and improves nitrogen balance in non-oliguric acute renal failure. Wien Klin Wochenschr 2007;119:218-222. 
36. Greig PD, Elwyn DH, Askanazi J, Kinney JM. Parenteral nutrition in septic patients: effect of increasing nitrogen intake. Am J Clin Nutr 1987;46:1040-1047.

37. Shaw JH, Wolfe RR. An integrated analysis of glucose, fat, and protein metabolism in severely traumatized patients. Studies in the basal state and the response to total parenteral nutrition. Ann Surg 1989;209:63-72.

38. Scheinkestel CD, Kar L, Marshall K, Bailey M, Davies A, Nyulasi I, Tuxen DV. Prospective randomized trial to assess caloric and protein needs of critically ill, anuric, ventilated patients requiring continuous renal replacement therapy. Nutrition 2003;19:909-916.

39. McCowen KC, Friel C, Sternberg J, Chan S, Forse RA, Burke PA, Bistrian BR. Hypocaloric total parenteral nutrition: effectiveness in prevention of hyperglycemia and infectious complications-a randomized clinical trial. Crit Care Med 2000;28:3606-3611.

40. Masiero E, Agatea L, Mammucari C, Blaauw B, Loro E, Komatsu M, Metzger D, Reggiani C, Schiaffino S, Sandri M. Autophagy is required to maintain muscle mass. Cell Metab 2009;10:507-515.

41. Vanhorebeek I, Gunst J, Derde S, Derese I, Boussemaere M, Guiza F, Martinet W, Timmermans JP, D'Hoore A, Wouters PJ, et al. Insufficient activation of autophagy allows cellular damage to accumulate in critically ill patients. J Clin Endocrinol Metab 2011;96:E633-E645.

42. Derde S, Vanhorebeek I, Guiza F, Derese I, Gunst J, Fahrenkrog B, Martinet W, Vervenne H, Ververs EJ, Larsson L, et al. Early parenteral nutrition evokes a phenotype of autophagy deficiency in liver and skeletal muscle of critically ill rabbits. Endocrinology 2012;153:2267-2276. 